\title{
FAMÍLIAS DAS CLASSES POPULARES: TRADIÇÃO E MUDANÇA
}

TRADITION AND CHANGE IN POPULAR CLASSES'S FAMILIES

Sylvia Leser de Mello ${ }^{1}$

MELLO, S. L. Famílias das Classes Populares: Tradição e Mudança. Rev. Bras. Cresc. Des. Hum., São Paulo, IV(1), 1994.

Resumo: As famílias das classes populares, na cidade de São Paulo, têm sido vitimadas pelas condições adversas de sobrevivência na cidade, uma vez que são, quase todas, de origem migrante. Sofrem, ainda, dois processos simultâneos de segregação e desqualificação. Este artigo discute, brevemente, as noções de tradição e mudança vividas pelas famílias das classes populares urbanas, enfatizando as diferenças culturais e a necessidade de adaptação aos desafios que o meio urbano propõe. Esses desafios estão presentes nas transformações dos padrões de autoridade masculina e na construção de novas modalidades de vida familiar.

Palavras-chave: Família, papéis familiares, classes populares.

Summary: This paper deals with the changing familiar life of migrants in São Paulo's city. In the urban environment they suffer two simultaneous processes:segregation and disqualification. We discuss, briefly, tradition and change, experienced by the urban popular classes's families, proposing cultural differences as a partial explanation for the difficult task of adjustment. This adjustment refers more specifically to changes in the patterns of authority which affects the family and to the different ways of dealing with them altering family organization.

Key-words: Family, familiar roles, popular classes.

1 Profa. Dra. do Departamento de Psicologia Sodal e do Trabalbo - Instituto dc Psicologia da Universidade de São Paulo. End.: Av. Prof. Lúcio Martins Rodrigues, Trav. 4, n 399, bloco 23 Cidade Universitária São Paulo - SP, CEP 05508-900 Fone: (011) 211-2965 Fax: (011) 818-4462. 
"Barbárie, cultura as sociedades ditas bárbaras têm uma cultura e as que se chamam civilizadas adquirem urna à custa de esféricos, para o melhor ou para o pior; puritanos, estetas, sociedades altamente militarizadas ou espírito de empreendimento capitalista fazem parte também do segundo gênero. O drama das grandes invasões desenrolou-se menos na ruína do aparelho imperial, na economia ou na demografia que em outro campo, onde se distinguem, por exemplo, pessoas que lêem e outras que não fazem disso urna questão de honra, populações treinadas para trabalhar duro e outras que não passaram por esse treinamento. Tal vontade inconsciente de se esforçar não se deve à escola ou às instituições, que são, antes, conseqüências disso; é inculcada pelo que erroneamente se denomina educação, ou seja pelo exemplo que, sem querer apresenta um grupo social em que se reproduz essa vontade de autoestilização. Sem querer, por certo, pois, à menor suspeita de que os pais formulam frases que não assimilaram, desfaz-se a evidência da ficção e os filhos já não os ouvem. Para ter crédito os sermões paternos precisam da garantia de uma força real. Ora, no Ocidente, com as grandes invasões do século $\mathrm{V}$, esvaece-se tal força, interrompe-se portanto a tradição da auto-estilização e inicia-se o que é para nós ‘ a noite da Alta Idade Média’ Isso desvenda um traço antropológico: o esforço cultural, esse trabalho de auto-educação que se pratica apenas em certas sociedades e, como toda tradição, não se poderia incutir deliberadamente ou à força Esse esforço, pois, nada tem em comum com o que os críticos chamam de necessidade do trabalho e da repressão: nenhum voluntarismo pode substituir as realidades da força ou minorar a humilhação, seria antes um desastre. O esforço sobre si mesmo nada tem de necessário ainda que permaneça eficaz; assemelha-se mais a uma ambição, a um jogo, a um luxo, até a um esnobismo. E alguns detestam a cultura por isso mesmo, por seu esforço contra a natureza, e não só por seu conteúdo de classe, o que quer que pretendam”. PAUL VEYNE (1990).

Há quarenta ou cinqüenta anos a cidade de São Paulo vem sendo sucessivamente invadida por camponeses pobres ou empobrecidos do norte e do nordeste do pais, assim como de zonas miseráveis de Minas e Goiás. Essas ondas migratórias não podem, é certo, ser comparadas às invasões dos bárbaros que, pacificamente, mudaram a face de Roma e do ocidente no inicio da Idade Média. Longe de mim a intenção de sugerir esse anacronismo. O que a longa citação de Paul Veyne lembra é que, embora os efeitos macro-sociais dessas migrações sejam conhecidos, há mais, nesses movimentos, do que simplesmente contingentes de pessoas que se deslocam e se recolocam espacialmente, mudando os contornos do campo e das cidades. Os efeitos e problemas ladeados pelas populações que assim se movimentam no interior do pais, e das populações dos locais para onde elas se deslocam, não podem ser bem descri- tas apenas pelas transformações vistas a olho nu.

Este artigo expõe alguns dos processos de transformação que as populações urbanas mais recentes sofrera e algumas alterações que promoveram no panorama urbano, sobretudo aquela imensa maioria da população que veio para a cidade e que permanece invisível e banal, que não é matéria de escândalo para a midia, tocando o seu dia-a-dia como qualquer outro cidadão que necessita trabalho para sobreviver.

Os nossos migrantes provocaram mudanças fundamentais na cidade de São Paulo, assim como fora modificados por ela. A forte atração exercida pelo crescimento industrial de São Paulo, e a pobreza dos estada de origem, são as causas desse efeito que denominam, migração, mas suas mais fortes conseqüências são hum nas. Mais ainda, o crescimento da urbanização não é uma particularidade nossa mas é resultado da expansão do capitalismo: “ A urbanização que se estende até os cal pois é uma urbanização degradada e degradante. Em vez de absorção e reabsorção do campo pela cidade, em vez da superação da oposição entre ambos, há deterioração recíproca: a cidade rebenta pelas periferias e a aldeia decompõe-se; 0 incerto tecido urbano que prolifera em vários países tem como resultado um magma informa os bairros de lata, a Megalópole” (LEFEBVRE, s.d).

Os problemas que quero desenvolver dizem respeito à conformação de um contingente de pessoas que conseguiu urbanizar-se à custa de um processo violento de aculturação, carregado de desvalorização e preconceito. Nesse processo vão se construir novas identidades subalternas e deteriorar-se as bases culturais da autor time A família é uma dessas bases profundamente afetada pela estigmatizarão.

As ondas de migração para São Paulo sucedem-se ininterruptamente durante meio século. Se elas mudança face da cidade, expandindo suas fronteiras, oferecendo mão-de-obra para a indústria que cresce, aumentando demandas por educação e saúde, seus protagonistas te também, que sacrificar à cidade uma parcela grande equipamento cultural. À ruptura com o conhecimento d coisas do campo, inútil na cidade, acrescentamse perspectivas culturais muito diferentes. A cidade é local privilegiado para a exposição das contradições inerente ao sistema de classes. Nela, as complexas hierarquias geradas pela divisão do trabalho não podem sofrer disfarces. Pelo contrário, as diferenças de renda expõem brutalmente.

Nestes últimos cinqüenta anos, grandes transformações de várias ordens afetaram o mundo todo, e o mi aparente reflexo delas é a rapidez da mudança tecnológica; Na cidade elas são mais visíveis e alteram a vi de todos os segmentos da população. Mas alteram de 
modo diverso, segundo a maior ou menor possibilidade de acesso aos seus beneficias que os diversos estratos da população possuem. Também o equipamento cultural não permite aos segmentos mais empobrecidos o pleno acolhimento de mudanças significativas. Um exemplo muito claro desse fenômeno é o abandono de práticas tradicionais na solução de problemas menores de saúde e a maciça automedicação sem controle médico.

Como compreender os movimentos de transformação que as famílias urbanas de baixa renda, oriundas do campo, vêm realizando? Como apreender as imagens, as representações mentais, que fazem de si mesmas, no interior de uma sociedade que as segrega nitidamente, quer como habitantes de bairros longínquos ou de favelas e cortiços, bem como vetando-lhes acesso às profissões com maior exigência de qualificação?

As mudanças na esfera familiar talvez sejam as menos perceptíveis, de todas as que ocorreram no terreno dos valores e da moral, porque a idéia de família guarda muito, ainda, certos aspectos valorativos próximos do sagrado e, porque, as formas mais tradicionais de representar a família constituem uma defesa psicológica, face às dificuldades concretas de realizar as representações ideais.

Se os movimentos que tiraram as pessoas do campo, levando-as a invadir a cidade, são bem conhecidos, não se reconhece com facilidade que as necessárias adaptações, provocadas pela ruptura com um modo perfeitamente estabelecido de vida pela tradição, envolvem a elaboração, acelerada pelo contato com os meios de comunicação de massas, sobretudo a televisão, de costumes e hábitos que conflitam com aquela tradição $\mathrm{O}$ modo como encontram moradia e trabalho na cidade, a frequência à escola, a distancia que vai se estabelecendo entre as gerações mais velhas e os jovens, já nascidos aqui e aqui criados, todos esses elementos entram na reorganização da família. As gerações mais velhas, que fizeram a migração, não tiveram acesso à escola. A grande maioria é analfabeta. Por mais precária que seja a escola que se abre aos seus filhos em São Paulo, há uma conquista real nas condições culturais das novas gerações. A cidade muda a escala em que se dá a sociabilidade: a experiência do campo, sobretudo nos pequenas sítios isolados - quero ressaltar que a distancia temporal dessas experiências é de 30 ou 40 anos - era limitada aos vizinhos mais próximos, à família, e às esporádicas visitas ao vilarejo, local da igreja e das casas comerciais, e onde compravam o sal e o querosene e vendiam o pequeno excedente. Um trabalho de Psicologia Social, que tenha pretensões de avançar o conhecimento sobre as famílias de classes populares urbanas, não pode desconhecer sua história, não só do ponto de vista macro social ou econômico, como dos valores e tradições que estão na origem da sua visão de mundo. De certo modo é preciso fazer psicologia social histórica, aliada à história cultural, trabalhar com os conteúdos das representações tradicionais, sobre as quais a cidade vai atear, descobrir como rearranjam os valores no mundo urbano.

A família, como instituição, encarregada dos cuidados e da socialização das novas gerações, não é uma abstração. Ela deve ser pensada não como um organismo fixo e imutável mas, ao contrário, permeável às pressões que caracterizam a vida das populações urbanas pobres, porque a proximidade com padrões muito próximos da miséria, a continua experiência da simples sobrevivência, obrigam-na a tornar flexíveis não só mecanismos adaptativos de ordem econômica, mas também de ordem emocional e afetiva.

Se do ponto de vista da psicologia a família constitui o centro das trocas afetivas, que representam os padrões que vão estabelecer a qualidade das relações humanas, os conteúdos culturais desses padrões têm uma importância fundamental na compreensão das transformações que afetam a forma da família das classes populares, pois se é possível trocar um espaço geográfico por outro, os modos peculiares de pensar o mundo, fruto da educação e da prática da convivência, não são tão facilmente abandonados.

As famílias originarias da cidade, ou aqui radicadas há muitas gerações, não estão imunes a essas transformações. Na verdade, elas afetam a todos ${ }^{2}$. Contudo, uma população que se transferiu há pouco, rompendo abruptamente com modos de vida tradicionais, e que não encontrou um ambiente propício ao seu desenvolvimento, integrando-se marginalmente na sociedade, sofre de modo diferente essas transformações. Elas não são, como é evidente, do puro âmbito das mudanças materiais, embora estas tenham importância A experiência da escassez não nasce na cidade. Pelo contrário, ela é constitutiva da experiência original de vida rural e responsável, em grande parte, pelo movimento migratório. Na cidade, no entanto, desenvolvem-se de modo muito mais claro as estratificações sociais, até mesmo em termos espaciais. Os espaços ocupados pela população migrante mais recente, são espaços da exclusão. Esta exclusão vai dar um conteúdo simbólica diferente à sua participação na vida urbana. As contingências especiais a que se submetem para sobreviver na cidade, e à cidade, permitem radicalizar certas transformações na organização da família que, na verdade, não são novas em São Paulo. Uma delas é a família matrifocal, encontrada na história da cidade já no inicio do século passado (DIAS, 1984). Nessas popula-

2 Veja-se, por exemplo, em relação às famílias de cidades médias altas, o excelente trabalho de Tânia Salem “O Velho e o Novo”. 
ções que, historicamente, se vêem obrigadas a abandonar os lugares onde estão, para buscar condições um pouco menos adversas de vida, as mulheres têm mais permanência, sua constância é a garantia da continuidade da família, enquanto os homens se vão e reconstituem os laços familiares com outras parceiras, em outros lugares.

É preciso, também, chamar a atenção para dois fenômenos que participam do quadro de mudanças. O primeiro, que é o trabalho feminino, não é exclusivo da cidade mas aqui se reveste de novas características. O segundo é uma transformação das imagens mentais ligadas ao mundo da infância e da representação da criança, por certo não de todo realizada nas populações mais empobrecidas, mas perceptível na forma como os adultos se relacionam com as crianças e com a questão da educação escolar.

O trabalho feminino na cidade, como o próprio trabalho masculino, passa por transformações de monta. Embora grande parte da mão-de-obra feminina migrante acabe engrossando o contingente de empregadas domésticas, o que não muda o conteúdo das ocupações, a qualidade do emprego é distinta. O trabalho doméstico não é, como no campo, uma atribuição natural (com todo o sentido de tradição que se possa dar a ele) mas sim, parte da divisão do trabalho num universo mais amplo do que o doméstico. A empregada doméstica ganha um salário, recebe dinheiro pelo que realiza na casa de alguém que é seu empregador. O salário recebido a situa numa escala de funções, que por sua vez, a situa numa hierarquia do todo social. Nessa perspectiva ela está em igualdade de condições com o homem. Embora sua experiência e sua socialização a tenham preparado para a submissão à ordem masculina do mundo, ao longo do tempo a percepção do lugar que o seu salário ocupa, no universo familiar e na sobrevivência de todos vai não só permitindo a mudança da imagem de gênero, como também, a imagem de suas funções no âmbito da família. A importância do público e do privado altera-se, bem como alteram-se as dimensões de sua participação nessas esferas. O domínio da autoridade, exclusivamente masculino, sofre a interferência dos novos papéis que a mulher desempenha fora de casa, e a autoridade masculina deixa de ser inquestionável. Uma das mais importantes experiências, nesse sentido, é a participação em atividades coletivas, mesmo quando se realizam no próprio bairro, ou quando se transferem à participação em movimentos populares, que têm nas mulheres seus valores mais expressivos (SPOSITO, 1993). Ao mesmo tempo são criadas instâncias na sociedade civil que denunciam a violência doméstica contra a mulher, gerando providências públicas, como as delegacias da mulher. Confrontando depoimentos de mulheres que passaram quase toda a sua existência no campo, e de outras que aprende- ram as normas próprias da cidade, as representações da autoridade são diferentes. Não negam o poder que o gênero masculino deve possuir dentro da família, mas é possível detectar ambiguidades no discurso e observar as maneiras irônicas de tratar a divisão tradicional de papéis (FONSECA, 1992).

Mudaram os tempos e com igual força mudaram as mulheres. Dentro dos limites de suas possibilidades elas prezam agora a autonomia, permitida pelo salário e consentida pelos companheiros. Quando saem do emprego doméstico para as fábricas que representam, na perspectiva delas, um grande passo para a sua realização pessoal, e a plena introdução ao mundo urbano e da modernidade, a própria concepção de trabalho se transforma: as empresas, com seus horários rígidos e o controle estrito sobre o tempo e distribuição das tarefas, eliminam os últimos vestígios de naturalidade que o trabalho feminino ainda possuia. Elas podem assumir a sua condição de trabalhadoras, para o melhor e o pior. Em alguns depoimentos, a trajetória de trabalho da roça à fábrica é a narrativa de uma vitória sobre as condições culturais desfavoráveis que tiveram que enfrentar, a batalha pela criação dos filhos sem a ajuda do marido, a realização pessoal de crescimento e de ascensão. No entanto, o forte componente autoritário difuso na sociedade brasileira, mascara as reais dimensões da autonomia da mulher e as transformações da autoridade no interior da vida familiar.

Aquilo que parece mais tranquilo, para as mulheres de certos segmentos das classes médias e médias altas, não o é para as classes populares. A educação escolar, a convivência com formas de cultura menos massificantes do que a televisão, a participação no mercado de trabalho, que era exclusivo dos homens, e a socialização mais flexível em relação à divisão dos papéis na família, permitem àquelas mulheres enfrentar com menos problemas as mudanças na área da autoridade doméstica Para as mulheres migrantes a lenta transformação dos valores familiares não facilita a compreensão das alterações quando elas ocorrem. Nesse sentido, as mulheres mais velhas não se permitem pensar que possuam qualquer autoridade, embora, de falo, tenham sido as educadoras das crianças em tudo o que diz respeito à aprendizagem da vida social.

No modo de vida das populações rurais a autoridade do homem era visível, porque ele dominava o conhecimento necessário à sobrevivência e dai tirava sua força A cidade transforma essa relação, porque torna em grande parte ineficazes as bases sobre as quais estavam assentadas as premissas da autoridade masculina. A mutação da autoridade, e 0 reconhecimento de que ela não é atributo exclusivamente masculino, transforma a organização da vida familiar. Nos bairros populares a figura masculina não é indispensável para que um grupo se apresente como 
uma família. Mais ainda, essas figuras podem ser frágeis, em seus aspectos tradicionais de provedores, presas constantes do desemprego ou do emprego irregular e marginal.

O resultado de alguns anos de observação e de convivência com famílias de um bairro da periferia de São Paulo (MULO, 1988 e GOMES, 1987) mostra, com muita clareza, que os modelos de família nuclear, baseados nos eixos de gênero e idade são apenas modelos ideais, fórmulas de autoridade e de dominância, pelos mais velhos ou pelos homens, que não encontram apoio na realidade.

Entretanto, longe de diminuir a dimensão que a família ocupa no universo subjetivo dos sujeitos, cresce ainda mais sua importância afetiva, como ponto de referência e de orientação para os seus membros. Em parte porque a cidade não oferece abrigo seguro para a dimensão afetiva, dado o caráter circunstancial e anônimo das relações humanas que aqui se estabelecem. A multidão isola cada sujeito dentro de si mesmo. Em parte devido à extensão geográfico da metrópole. Mas, sobretudo, porque o trabalho, que consome o maior tempo da vida dos sujeitos, é destituído de significado. A população de baixa renda realiza, de modo geral, tarefas mecânicas, pesadas, mal remuneradas, vistas quase sempre com desdém pelas classes médias. Quando no ambiente de trabalho, ou associado a este, os sujeitos encontram oportunidade de expressão, como nos sindicatos ou associações de classe, não só é possível a consolidação das aspirações à individualidade, como se formam espaços propícios à criação de laços de afeto. Embora a filiação a essas associações possua um aspecto cultural que não faz parte da experiência das gerações mais velhas, encontramos, nas famílias estudadas, um número grande de jovens que pertencem aos sindicatos ou militam em partidos políticos.

De qualquer maneira, a família constitui o centro privilegiado das trocas afetivas e da constituição do universo simbólico de classe. O grande problema que o pesquisados enfrenta para compreender como se dão as relações afetivas, e como se organizam no seio da família é, em geral, a proposta etnocêntrica invisível mas presente, nas suas observações. O que podemos observar é um fenômeno de polimorfismo, uma grande variabilidade nas formas de organização das famílias, e de divergência dos padrões tradicionais de divisão de papéis.

Se analiso os dados procurando recuperar seu sentido original, as famílias que se oferecem à observação não são desorganizadas ou desestruturadas. Muito ao contrário, representam um imenso esforço dessas populações para dar ordem ao seu universo, oferecer uma face sólida à realidade, que não responde generosamente ao seu esforço de sobrevivência Sei que essas observações contradizem estudos que demonstram que as classes populares são mais conservadoras do que as classes médias e que não há, de falo, mudança mas desestruturação. A resposta que posso oferecer é que há grandes contradições e ambivalências no processo de transformação das famílias nas sociedades ocidentais, que aparecem com muita frequência nos depoimentos de homens e mulheres. As classes populares não são, nesse sentido, mais ou menos conservadoras. Vivem, na cidade, um processo diferente de acomodação às exigências urbanas, oriundo de condições extremamente precárias de vida.

Um dos aspetos mais originais dessa acomodação é o bairro da periferia. Esse "espaço criado” pelo capitalismo, como afirma Lefebvre, é recriado pelos seus habitantes que dele se apropriam efetivamente, fundando um lugar claramente diferenciado do resto da cidade, com moradias autoconstruidas, em terrenos muito pequenas, casas sem acabamento externo, sem cuidados maiores com o resto do terreno, ruas de terra, com águas servidas correndo em regas, e outros sinais de exclusão e abandono. Algumas áreas são cobertas por favelas, com barracas feitos de sucata, ruas estreitas e tortuosas. Uma característica fundamental desse tipo de aglomeração urbana é a ausência de privacidade, a porosidade das moradias, tornando-as permeáveis aos vizinhos mais próximos e a pequenez delas exigindo a proximidade física dos moradores no seu interior.

Essa experiência não permite 0 isolamento e transfere para a comunidade um certo controle sobre os acontecimentos privados. Nem ventura nem desgraça podem ser escondidas por muito tempo. Embora não possuam o fechamento ao mundo externo que caracterizava as comunidades das aldeias, os bairros populares possuem traços do que se poderia chamar uma coletividade. E como são mediadores das adaptações e criações culturais para os seus habitantes, ganham aspectos semiurbanos próprios, porque são e não são a metrópole. A começar pela distancia em que se situam em relação aos vários centros que uma cidade como São Paulo possui: centros comerciais, centros culturais, centros de lazer. Tudo isso tem que ser recriado no bairro, com os seus recursos limitados. Habitantes da cidade, os moradores dos bairros das periferias ai ficam segregados, retomando velhas práticas comunitárias, como a sociabilidade reduzida aos habitantes do local, os mutirões, a ajuda mútua, a criação de aglomerados de famílias nucleares. Há uma expansão das características peculiares da vida em família para o bairro como um todo, tornando muito denso o seu ambiente afetivo.

A segregação acarreta riscos de várias naturezas. Dentre eles a carga de violência e de marginalidade que os moradores dos bairros têm que suportar, quer da marginalidade que ali se instala, o que gera tensão e medo, 
sentimentos que fazem parte da cultura do bairro, quer dos órgãos de repressão, que não hesitarn em invadir o bairro em verdadeiras operações de guerra. Esta situação projeta nos moradores, na sua imensa maioria homens, mulheres, jovens e crianças que trabalham "pesado", a sombra da suspeita permanente. Como diferenciar-se da massa que, sem distinção, recebe um tratamento degradante? Como elaborar ainda essa humilhação, que se vem somar às outras vividas no quotidiano? A resposta ao problema do estigma de que são vítimas é quase sempre dado pelo trabalho, que lhes garante uma precária identidade não marginal, e pela sociabilidade intensa no interior do próprio bairro. Para analisar esse tipo de resposta podemos nos valer de Freud ${ }^{3}$ e sugerir que, na verdade, na ausência de fortes modelos identificatórios, as identificações são mútuas, característica típica da massa. Estamos, assim, diante de uma contradição: os bairros permitem e facilitam a adaptação dos trabalhadores, permitem-lhes uma rica sociabilidade, mas favorecem o isolamento e o distanciamento de questões mais próprias do âmbito público, como a política, e dificultam, pela excessiva coletivização dos espaços geográficos e psicológicos, o processo da autonomia e da individuação. Este é mais um risco da segregação, prejudicial não apenas à população de baixa renda mas ao pais como um todo, tão carente da verdadeira cidadania. E este risco, como bem afirma Rouanet é “a regressão ao homogêneo e ao indiferenciado”. “...Afetivamente empobrecido, o homem encontra calor e amparo na comunidade a que pertence ou à qual se filia, através dos laços libidinais com os outros membros do grupo. Angustiado com a obrigação de pensar por si mesmo, transfere ao líder a tarefa da reflexão autônoma e recebe da comunidade opiniões já prontas” (ROUANET, 1993).

O segundo fenômeno que mencionei- a transformação das imagens mentais e da representação da infância - já foi bem descrito em outros trabalhos (ARIES, 1978). A experiência das mulheres que vão trabalhar como domésticas enriquece a sua percepção da infância, já presente nas classes médias, modificando a concepção da maternidade. É preciso registrar, no entanto, que a relativa facilidade que as mulheres encontram para controlar a sua fecundidade, tem dois aspectos diferentes e complementares, refletindo-se na família e na sua composição. O primeiro está muito relacionado com o problema da autonomia e com a substituição do destino materno pela escolha da maternidade. Este controle que a mulher passa a ter sobre o seu corpo, nas classes populares urbanas, é ainda um tateio que tem mais a ver com a sobrevivência, e com as aspirações de ascensão social para a prole, do que com a real autonomia. Por outro lado, há uma explica são da sexualidade adolescente e o número de mães muito jovens cresce a cada dia. $\mathrm{O}$ segundo, lembra que o acesso que a cidade possibilita aos cuidados médicos, ainda que excessivamente prejudicado pela qualidade do serviço que é oferecido à população, preserva não só a vida das mulheres, melhorando as condições do parto e do pré-natal, como aumenta grandemente a possibilidade de sobre vivência das crianças.

Embora dados do IBGE afirmem que há um contingente de sete e meio milhões de crianças de 7 a 14 anos de idade que trabalham no Brasil (PEREIRA, et al 1994), as crianças não são mais, pelo menos nas zonas urbanas, vistas pela família somente como trabalhadores em potencial, como nas zonas ainda de forte influência rural. A infancia ganhou um terreno próprio, o reconhecimento de que é uma etapa da vida para ir à escola preparar o futuro e brincar. A severidade familiar cede lugar à tentativa de compreensão do universo infantil Aqui, como em todos os aspectos referentes à vida familiar, as contradições são grandes: as punições corporais são amplamente empregadas e o pai, quando está presente na família, parece ter a última palavra quando se trata de admoestar ou exigir o bom comportamento. Mas, e não foi raro encontrarmos esses depoimentos, os pais assumem de boa vontade tarefas domésticas. Entre os casais mais jovens, quando ambos trabalham, é comum a dividi são das tarefas dentro de casa, até mesmo o cuidado dos filhos. O pai distante, cujo olhar vigiava de longe c cumprimento das obrigações que competiam a todos os membros da família, humaniza-se, aproxima-se e como vê-se com as brincadeiras infantis. Em alguns depoimentos as mulheres mais velhas relatam as relações quase sem palavras que mantinham com seus senhores! os maridos. E relatam a interdição de falar que pesava sobre as crianças na presença de estranhos. Hoje todos falam. As palavras distribuem-se igualmente pelo grupo familiar, sem interditos.

Apesar de todos os fracassos, os pais atribuem à escola, ainda, uma grande importância para a vida futuro das crianças. Ela é o símbolo da possibilidade de mudança de status, de passagem dos empregos pesados para formas mais amenas de ganhar a vida Pode-se falar dá sentimento da infancia, no reconhecimento de que é a fase propícia da vida para aprender aquilo que vai ser útil para o adulto. No entanto, os números sobre o trabalhe infantil e juvenil não permitem esconder a realidade. Há um longo caminho a percorrer entre o desejo dos pais, de oferecer aos filhos uma vida melhor, e a sua possibilidade de realizá-lo. Ouçamos Benjamin: "A criança

3 Freud elabora suas concepções sobre a massa e o problema das identificações sobretudo no ensaio "Psicologia de las masas y analisis del yo", mas a sua preocupação com o tema aparece também no "El malestar de la cultura e "El porvenir de una ilusión”. 
proletária nasce dentro de sua classe. Mais exatamente, dentro da prole de sua classe, e não no seio da família. Desde o início ela é um elemento dessa prole, e aquilo que ela deve tornar-se não é determinado por nenhuma meta educacional doutrinaria, mas sim pela situação de classe. Esta situação penetra-a desde o primeiro instante, já no ventre materno como a própria vida, e o contacto com ela está inteiramente direcionado no sentido de aguçar desde cedo, na escola da necessidade e do sofrimento, sua consciência. Esta transformase, então, em consciência de classe. Pois a família proletária não é para a criança melhor proteção contra uma compreensão cortante do social do que seu puído casaco de verão contra o cortante vento invernal” (BENJAMIN, 1984).

O grupo familiar varia muito mas é, ainda, a resposta mais satisfatório para a criação das crianças. Essa variabilidade não pode ser tomada, inconsequentemente, como desestruturação. Adaptação e mudança, sim. A presença de crianças na rua ou de crianças de rua não significa a dissolução dos laços familiares de todas as famílias de baixa renda. Abandono e violência existem? Sim. Mas para cada criança abandonada podemos contar milhões de crianças que vivem com suas famílias. Para cada jovem, que empunha uma arma e assalta, podemos contrapor um milhão que enfrenta o trabalho duro e a vida qua-

\section{BIBLIOGRAFIA}

ARIES, P. A história social da criança e da família. Rio de Janeiro, Zahar, 1978.

BENJAMIN, W. Reflexões: a criança, o brinquedo, a educação. São Paulo, Surnmus, 1984, p. 90.

DIAS, M. O. Quotidiano e poder em São Paulo no século XIX. São Paulo, Brasiliense, 1984.

FONSECA, C. Honra, humor e relações de gênero: um estudo de caso. In COSTA, A. O.; BRUSCH[NI, C. Uma questão de gênero. São Paulo, Rosa dos Ventos, 1992.

FREUD, S. Psicologia de las macas y analisis dei yo. Madrid, Biblioteca Nueva, 1973.

El molestar en la cultura. Madrid, Biblioteca Nueva, 1973.

El porvenir de una ilusión. Madrid, Biblioteca Nueva, 1973.

GOMES, J. V. Socialização: um estudo com famílias de migrantes da periferia de São Paulo. São Paulo, 1987. [Tese de doutorado USP]. se sem perspectivas. Que a mídia possa falar indistintamente de pobres e bandidos como sinônimos, que possa sempre culpabilizar as famílias e degradar a criança alcunhando-a de “menor”, talvez seja inevitável. Ela veicula o preconceito dominante, apega-se à facilidade do estereótipo. Mas o pesquisados possui outros compromissos, e grande parte da tarefa do conhecimento é discerriir as marcas do etnocentrismo quando se depara com composições culturais diferentes. Recorro, mais uma vez a Rouanet: "O etnocentrismo nega, de todo, ao povo "primitivo” a condição de sujeito. Em vez de reforçar o status quo pela abstenção, ele o reforça pela intervenção. Em vez de idealizar a cultura alheia, ele a despreza. Em vez de ajudar a promover uma mudança emancipatória, reforça as heteronomias já existentes. Todo etnocentrismo é um particularismo. E a agressão de uma cultura por outra, violando padrões universais de justiça” (ROUANET, 1993).

Tratando-se de saúde pública ai estão as campanhas de vacinação que, conduzidas com respeito pelas diferenças culturais, mas valorizando esta genericidade que é a saúde como um bem universal, obtiveram sucesso no controle e erradicação de doenças. Há duas postes, porém, que só podem ser vencidas com um grande esforço coletivo: a miséria e a ignorância, com o seu triste corolário da violência, que degradam a nação.

LEFEBVRE, H. O pensamento marxista e a cidade. Lisboa, Ulisséia, s. d., p. 160.

MELLO, S. L. Trabalho e sobrevivência. São Paulo, Ática, 1988.

PEREIRA, I. et al. Trabalho do adolescente: mitos e dilemas. Série Defesa da Criança e do Adolescente, 2, maia, 1994.

ROUANET, S. P. Mal-estar na modernidade. São Paulo, Companhia das Letras, 1993, p. 109278.

SALEM, T. O velho e o novo. Petrópolis, Vozes, 1980.

SPOSITO, M. P. A ilusão fecunda. São Paulo, Hucitec-Edusp, 1993.

VEYNE, P. org.; ARIES, P. dir.; DUBY, G., dir. História da vida privada. São Paulo, Companhia das Letras, 1992, p. 401-402, V.l.

recebido em: 12/08/94 aprovado em: 04/10/94 